\title{
College and University Mergers: Impact on Academic Libraries in China
}

\author{
Hong-Wei Huang \\ Translated by Sha Li Zhang
}

\begin{abstract}
Since the early 1990s, under a state-planning program, individual colleges and universities in China began to merge with much larger universities. Such mergers have been a part of China's higher education reform. The wave of mergers among colleges and universities will have a far-reaching influence on China's academic libraries. In this paper, the author attempts to explore positive outcomes for academic libraries, present anticipated challenges, and offer possible solutions in the library merging process.
\end{abstract}

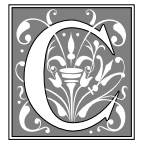

olleges and universities in China have been governed by several parent organizations. Some have been funded and managed by the state government. One example is Peking University, which has been funded by the State Educational Commission (the state government). Others have been funded and managed by each departmental ministry and provincial government. Beijing Medical University, for instance, has been supported by both the Ministry of Public Health and the Bureau of Higher Education of Beijing City. In the past, such a funding and management model, to some degree, has caused each college and university to function in isolation, has created duplicate programs among colleges and universities in the same geographic area, and has exacerbated competition for funds and resources among these schools. ${ }^{1}$

In the early 1990s, the State Council and the State Educational Commission in China required that colleges and universities improve the management system so that funding and resources for higher education would be better used. This plan was intended to enhance educational quality, improve institutional efficiency, and share educational resources. The plan also encouraged individual universities and colleges in the same geographic areas to merge or combine into one comprehensive educational entity. Under this plan, one hundred major universities were selected to be the first group to experiment in such mergers. These universities have traditionally had strong academic programs, resources, and infrastructures.

Hong-Wei Huang is the Library Director at the Hunan Senior College of Constructional Materials in Hengyang City, Human Province, People's Republic of China. Sha Li Zhang is Head of Technical Services at the Wichita State University Libraries; e-mail: zhang@twsuvm.uc.twsu.edu. The original version of this paper appeared in the Journal of Academic Libraries 17, no.3 (1999): 62-64. 
In 1993, Sichuan University and Cheng-du Science and Technology University became the first ones to merge into one educational entity named Sichuan Union University (recently, the name was changed back to Sichuan University).

The trend of college and university mergers will continue in China in the next decade.

Since 1997, the pace of college and university mergers has increased considerably. One hundred and ninety-five colleges and universities have merged into seventy-four major universities, and the names of eighty-five colleges and universities have been eliminated. An additional example of such a merger is Zhe-jiang University, which was formed by merging Zhe-jiang University, Hang-zhou University, Zhe-jiang Medical University, and Zhe-jiang Agriculture University. Today, Zhe-jiang University is the largest university in China. ${ }^{2}$

The trend of college and university mergers will continue in China in the next decade. Academic libraries that have affiliated with each college and university before the merger will function as one library system serving the entire merged university community. What will be the outcomes when these libraries merge? What kind of impact will these academic libraries experience? How do we respond to challenges brought forth by these mergers? In this article, the author hopes to explore these aspects and offer possible answers.

\section{Positive Outcomes for Academic Libraries}

There is no doubt that college and university mergers will have a far-reaching influence on China's higher education and on academic library services as well. The positive outcomes will include:

Collections: Combining materials from several libraries will create an enlarged collection that no single academic library could afford to acquire. The increased number of copies, volumes, unique titles, and formats will make library collections more comprehensive and more volatile than when the collections were located separately. Access to the greater number of library resources is definitely a plus for all merging libraries.

Acquisitions: In the merger process, many small schools are combined or become part of a larger university. The libraries of these small schools will benefit from combined acquisitions budgets that allow them to acquire desired materials. Because of such mergers, small schools will be able to receive funding levels that used to be granted only to large research libraries. They also will be able to take advantage of collection development and acquisitions expertise from the large libraries while selecting and acquiring materials.

Staffing: When libraries merge into one large organization, staff quality will improve. Adding staff members from several libraries together will increase the number of competent staff. In addition, morale will increase when a conducive and collegiate environment is present. The library will be able to redesign positions and organizational structure that serve the new library in a more efficient way. Duplicate positions will be eliminated. The library will have greater flexibility to redirect staffing to the most needed positions than formerly, especially in key technical and managerial positions. Therefore, the staff shortage that has existed in smaller libraries will be alleviated. Moreover, staff will be encouraged to stay current and to seek opportunities to learn new skills.

Services: When several colleges and universities merge, their teaching and research programs will be improved and enhanced. The state government has set a higher expectation for merging schools than for other schools in terms of teaching and research. On the other hand, merging colleges and universities also intend to quickly demonstrate advantages and benefits gained from mergers in order to obtain additional funding from the state government. Therefore, they ex- 
pect a higher quality of library services than ever before. Such an expectation presents the merging library with an opportunity to prove its importance within the university community. Library services will be improved.

Funding: Mergers will alleviate the situation of tight funds for library acquisitions. In principle, the state government, departmental ministry, and provincial government have committed to allocate more funds than before to support colleges and universities during the mergers, including additional funds to support libraries. Because each merging library will substantially reduce duplicate copies, the savings can be used to purchase more unique titles than previously. More-

\section{Duplicate administrative positions will be either eliminated or com- bined, and existing positions will be reassigned.}

over, after the mergers, the growing reputation of the university will enable the library to attract additional funding and donations from other sources.

Resource sharing: Before mergers, due to a variety of reasons in the past, resource sharing was a good theory that was never put into practice. Although many colleges and universities in the same geographic areas have talked about resource sharing for years, they have never taken any actions. The act of merging will enable libraries to achieve resource sharing. Many less-circulated items will then be accessible to the larger university community. Some special collections will demonstrate their values for meeting a variety of user needs.

\section{Anticipated Challenges for Library Services}

In addition to certain advantages, the wave of university mergers will bring about certain challenges. These challenges come from the following areas:

Library administration: Before merging, each individual library has its own administration team, including a library di- rector, associate/assistant directors, and department heads. In many cases, this group of people has worked together for a long time and has developed personal bonds. When the merger comes, the administrative teams from several libraries will have to be restructured because the need to have several library directors, numerous associate/assistant directors, and a dozen department heads no longer will exist. Duplicate administrative positions will be either eliminated or combined, and existing positions will be reassigned. Such changes will cause anxiety, resistance, and passive reactions among library administrators, especially in the case of conflict interests between the individual and the newly merged library.

Staff positions: Like administrative posts, library staff positions will face restructuring, elimination, combination, and reassignment. In academic communities, many staff have worked in the same library for years. They have lived in comfortable working zones. When libraries merge, they will be asked to work with staff from different libraries, perform at different positions, and assume different responsibilities. Those people often fear losing their comfortable zones. If merging libraries do not address these issues carefully, they will generate resistance and have a negative impact on staff morale.

Collection: During the mergers, several collection issues need to be resolved. First, if the library administration decides to eliminate small libraries and move all materials into the central library, this will cause an immediate space problem for the central library. On the other hand, if the library administration intends to keep the small libraries as branch libraries, the newly merged library will have to purchase multiple copies of certain materials for each site, which will tie up the new library's materials budget. Second, before the merger, each library had developed various specialized collections to meet its college or university's teaching and research needs. When libraries merge, fund- 
ing for those collections may be reallocated to purchase materials in a broader scope. Therefore, it will take a long time to reestablish collections that meet teaching and research needs of the newly formed interdisciplinary programs in the merging university. A gap will exist between the enhanced teaching and research programs and expectations of library materials. Third, in the past, due to the lack of coordination in acquisitions among academic libraries in the same geographic area, the libraries have many duplicate monographic and serial titles. When the merger comes, these duplicated materials will require additional space to be housed. For highly circulated items, multiple copies will enable the library to meet the user demand. However, less-circulated duplicates will add pressure to library shelves and space.

Online cataloging system: In past years, many four-year university libraries and junior college libraries installed online cataloging systems. These systems were developed either in-house or by different vendors. When these small libraries are merged into large academic libraries, all parties will face incompatible system issues. The merging libraries will have to invest substantial funds to have a unified online system in the next few years.

\section{Possible Solutions}

Based on the above observations and assumptions, the author offers the following possible solutions:

1. Put personal interests aside and keep integrity. Each library should respect decisions resulting from mergers from a higher authority. The college and university merger should be viewed as a onetime opportunity that will bring many benefits to all participants.

2. Plan ahead. Each library should prepare for the anticipated merger before the decision comes from the state government. An inventory list of such preparation should include:

- Collections: Each library should count its collections and share this information with other libraries. The libraries need to weed through the less-circulated multiple copies so that this group of materials will not have to be moved to the new library.

- Materials usage: Each library should collect data such as the number of registered patrons, circulated volumes, library services, and access methods. The number of patrons in the new library should be projected. Other preparation includes studying users' reading behavior and circulation patterns in the new library, and comparing policy and procedures among the merging libraries. These data will provide guidelines for the new library's acquisitions and services.

- Facilities: Each library should list data such as space, reading seats, automation system, hardware, software, and so on in order to prepare for combining online cataloging systems. Such data should be shared among merging libraries prior to physical moves.

- Personnel: Each library should provide a list of staff and their responsibilities and assignments to other libraries that will merge. Such a list will enable the new library administration to reassign positions and responsibilities based on individual skills and experiences.

- Acquisitions: A coordinating effort in acquisitions should be made among merging libraries. Each library should keep multiple monographic and serial copies to the minimum to alleviate shelf and space pressures in the new library. Each library should predict teaching and research needs of the university community after the merger. Acquisitions should be well planned, focused, and tied to programs in the merged university.

- Policy and procedures: A draft of policy and procedures for the new library should be in place to guide the merged library practices.

- Moving: Finally, each library will have to prepare moving some materials to the central library and at the same time relocate materials to branch libraries. Preparation should be in place prior to physical moves.

3. Form an inspiring and united library administration. This is the key to the suc- 
cess of the merged library. People on this administrative team should be capable, conduct themselves in a professional manner, and assume full responsibility for their work. Though these individuals will come from different libraries, they must work together and not allow gossip and activities from their previous libraries to interfere with their new responsibilities. They also will need to encourage staff to participate in creating new library practice and help the merged library implement operations in a short time frame.

4. Build a competent staff team. When the new library administration reassigns responsibilities in key positions, it should maintain balance among staff from different libraries and also work to avoid conflict. This will be most effective when an environment is established that will enable talented staff to grow and reach their potential. The new library administration also should recognize that staff coming from small libraries will need training to catch up with their colleagues from large libraries. Maintaining harmony among the staff is the most important component of the merged library.

5. Weed out less-circulated materials prior to the physical move. Each library should conduct its own weeding project before moving to the new library. The librarians should get rid of less-used multiple copies to avoid moving these materials to the new library. The weeding process will save much space.

6. Make a long-range plan. This is the most important step in merging libraries. The new library should have in place unified policies and procedures, a unified facility maintenance system, and a unified personnel policy. If the new library plans to set up branch libraries, it should implement the same policies and procedures so that the branch libraries will be real arms of the central library and not just the old libraries with new names.

7. Establish a central acquisitions, cataloging, and processing unit. A centralized processing unit will eliminate duplicate efforts, resources, and personnel. It also will help the merged library follow the same standards in processing materials.

8. Provide support for staff whose positions are eliminated. Due to reassignments in many merged libraries, some staff members will retire and some will go elsewhere to work. However, there will always be some library staff who will not be reappointed. The new library should make every effort to support these staff, including placing them in temporary positions so that they can stay current with new library practices and get reappointments in the near future.

Library mergers are new, complicated, and exciting in China. Librarians should devote their energy and efforts to ensure a smooth transition. The library's users will be the true beneficiaries of mergers.

\section{Notes}

1. Yuan-qing Zhou, "It Is Imperative to Increase the Pace of Higher Education Reform," Research in Higher Education, no. 1 (1998): 16-19.

2. Qiang Zhu, an e-mail exchange with the translator, Dec. 9, 1999. 